\title{
Las revistas científicas y la pandemia
}

\author{
Scientific journals and the pandemic
}

\author{
Lewis Pereiraa (iD; Yuly-Marcela Parra-Montoyab ${ }^{\text {iD }}$
}

Este número de la revista tiene características particulares porque de alguna manera nos encontramos en momentos de cambios, es decir, no es necesario que una revista cambie de rumbo cuando se renueva su editor en jefe, pero no siempre ocurre de ese modo. Un editor imprime siempre su estilo a las revistas sobre la política editorial y los detalles relacionados con la forma como se administra y gerencia, las metas que se propone, en fin, todo recibe un nuevo aliento. Las revistas científicas no son entidades abstractas o indeterminadas dedicadas a la divulgación del conocimiento, sino entidades insertas en procesos institucionales y sociales que son situados y se relacionan con quienes toman sus decisiones de forma directa.

Esto viene al caso porque el equipo editorial de la revista está siendo renovado, una importante colega se fue y otros nos encontramos ahora al frente con esta importante responsabilidad. Cuando esto ocurre se deben hacer los reconocimientos del caso, que no son muy frecuentes en el mundo editorial, en el sentido mirar hacia lo hecho. La jefe editora saliente, la profesora Marta Sahagún, realizó una destacada labor que le imprimió a la revista un renovado impulso, uno que antes no había conocido, llevándola a una nueva posición; la revista aumentó su calidad a tal grado que, por fin, ingresó en los índices y bases de datos internacionales más conocidos y todo, desde un esfuerzo y desvelos hechos en silencio. Es un camino recorrido en el que todavía falta mucho, pero que debe ser reconocido. Por eso queríamos dejar constancia de nuestro agradecimiento para con la profesora y su dedicación.

De otra parte, en lo que se refiere a la presente edición, los lectores encontrarán diversos temas de interés provenientes de tres campos o tres ciencias sociales que son la psicología, la educación y el trabajo social; entre ellos uno que, como era previsible, aborda el tema del COVID-19 y cómo ha incidido en la sociedad. La temática ahora forma parte de las preocupaciones de los científicos sociales, empeñados en medir sus consecuencias sociales, culturales y familiares. Se trata de una investigación que explora las redes de solidaridad familiar desarrolladas a partir de esta situación, ofreciendo detalles sobre el tipo de estrategias de sobrevivencia que se han conseguido. Es una investigación de enfoque cuantitativo, aunque no deja de lado la comprensión cualitativa de la data conseguida.

También se incluyen investigaciones de otros temas, como la relativa a los propósitos de vida en los excombatientes de las FARC, el conocido grupo guerrillero colombiano y la relacionada con la educación en Derechos Humanos y los acuerdos de paz de 2016, algo que, como se sabe, implicó una desmovilización de buena parte de los guerrilleros activos. La temática es relevante para el país y no deja de ser estudiada por los científicos sociales para los cuales ha sido todo un reto.

aEditor en Jefe, Corporación Universitaria del Caribe CECAR. revistabusqueda@cecar.edu.co

${ }^{\mathrm{b} E d i t o r a}$ Asociada. Corporación Universitaria del Caribe CECAR. revistabusqueda@cecar.edu.co 
En esta ocasión, la categoría "propósito de vida" o sentido de vida es tratado desde la psicología aportando conocimientos sobre el "nivel vital" de los excombatientes, una vez que regresan a la vida civil, evaluando ese choque en el paso del mundo militar, regido por las normas de la guerra y el mundo civil; la investigación vincula dichos propósitos de vida con la condición socioeconómica que llegan a alcanzar estas personas luego que realizan esfuerzos de integración. En cuanto a la reflexión sobre derechos humanos, se trata de un artículo análisis que da cuenta del proceso que ha seguido la sociedad colombiana en los últimos años o hasta donde los acuerdos han alcanzado los propósitos que perseguían y como, en dicho escenario, podría tener cabida una educación en los derechos humanos.

Sobre temas exclusivamente psicológicos incluimos tres investigaciones, una sobre la terapia de reminiscencia aplicada a los adultos mayores, otra sobre los aspectos formativos de la supervisión terapéutica en la formación de los psicólogos y otra sobre las habilidades visoperceptivas en los niños en el preescolar. La primera bajo la forma de una revisión de literatura especializada sobre el tema hecha por investigadores españoles y en escenarios europeos, sobre el recuerdo de largo plazo y sus posibles beneficios para conseguir que este sector de la población alcance un modo de vida más sosegado y feliz; se apuntala a la tesis de como recordar puede ser una terapia y se revisa literatura clave, bajo la guía de una experta en la materia reconocida internacionalmente. Sobre el artículo relacionado con la supervisión terapéutica la reflexión se centra en intentar deducir ideas claves que ayuden a pensar este importante tema y en cuanto al trabajo sobre las habilidades visoperceptivas se realiza un estudio de campo sobre las relaciones entre la percepción visual y la psicomotricidad en niños de preescolar en una de las ciudades colombianas más concurridas de la frontera con Venezuela.

Otro estudio explora la relación entre las condiciones de vida de la población joven en dos (2) ciudades y la felicidad urbana, un paper preparado por profesores de la Escuela Superior de Administración Pública (ESAP), la escuela de gobierno de Colombia y una importante institución. El proyecto recibió financiamiento del, ahora extinto, COLCIENCIAS, una entidad promotora que dio lugar al Ministerio de la Ciencia, Tecnología y la Innovación (MINCIENCIAS) en el transcurso de la gestión del actual presidente de Colombia. Se trata un papel de trabajo con una estadística sólida y un buen nivel de detalle, que explora aspectos claves sobre el tema. Algo que se debe hacer notar sobre este trabajo, es el hecho lamentable de que uno de sus autores, el profesor Ángel Emilio Muñoz-Córdoba, no pudo ver su publicación porque falleció en el transcurso del proceso editorial. Ciertamente, la población ha estado agobiada en el último año por causa del COVID-19 con la pérdida de familiares y amigos, y la comunidad científica no ha sido la excepción. A pesar de que las estadísticas internacionales señalan que la tasa de mortalidad de esta enfermedad se encuentra entre el $3 \%$ y el $5 \%$, su carácter masivo y omnipresente ha sido suficiente para que cada familia, por término medio, tenga un familiar entre las víctimas. El encierro ya lleva tantos meses que la sociedad ya ha comenzado a dar respuestas que tienden a estabilizarse como la migración hacia la virtualidad de muchas de nuestras actividades académicas, entre ellas congresos y buena parte de la labor académica de las aulas de clase, y esto, aunque parezca paradójico ha sido beneficio para el número de eventos que se realizan, ahora es más fácil reunir especialistas de cada país y ellos están más dispuestos a la virtualidad; también tenemos una mayor presencia del teletrabajo. De todas maneras, lamentamos hondamente la partida del profesor Muñoz.

Esperemos que todos los que leen la revista encuentren en este número conocimientos útiles que puedan servir para el desarrollo de sus investigaciones y de las ciencias sociales en general. 